\title{
Radiopeptide Imaging and Therapy in the United States
}

\author{
Michael M. Graham and Yusuf Menda \\ Department of Radiology, Carver College of Medicine, University of Iowa, Iowa City, Iowa
}

Radiolabeled peptides targeted against receptors on the cell surface have been shown to be remarkably specific and effective in the diagnosis and therapy of malignant disease. Much of the early work in this field took place outside the United States, but in recent years the research effort within the United States has accelerated. Most of the initial studies in the United States focused on somatostatin receptor ligands. ${ }^{111}$ In-pentetreotide was approved in 1994 and has been used extensively in the diagnosis and management of a wide variety of neuroendocrine tumors, particularly carcinoid. This work was extended to ${ }^{99 m}$ Tc-labeled analogs, and the most successful, ${ }^{99 m}$ Tc-depreotide, was approved in 1999. This agent was found to be accurate in the diagnosis of lung cancer, but it was not particularly successful because it was supplanted by ${ }^{18} \mathrm{~F}-\mathrm{FDG}$ imaging with positron tomography. More recently, studies with ${ }^{68} \mathrm{Ga}$-labeled somatostatin analogs were initiated in the United States. This effort was delayed relative to that in other parts of the world because of difficulty in obtaining the necessary generators and regulatory uncertainty, both of which are less of a problem currently. Several ligands are being developed to image melanoma through targeting of the melanocyte-stimulating hormone receptor. Other ligands are being developed to use the arginine-glycine-aspartate oligopeptide to target angiogenesis and to use bombesin analogs to target the gastrin-releasing peptide receptor for the diagnosis and potential therapy of prostate cancer. Peptide dimers that target 2 receptors simultaneously are also being constructed, potentially increasing the selectivity of the approach significantly. Radiopeptide therapy has been explored with these ligands, initially with high-dose ${ }^{111}$ In-pentetreotide. This step has been followed by U.S. participation in several trials with ${ }^{90} \mathrm{Y}-,{ }^{177} \mathrm{Lu}-$, and ${ }^{188}$ Re-labeled analogs. Some of these agents are now available clinically outside the United States, and it is important to design and conduct the appropriate trials so that this therapy can be offered within the United States.

Key Words: peptides; somatostatin; neuroendocrine tumor; carcinoid; melanoma

J Nucl Med 2011; 52:56S-63S

DOI: 10.2967/jnumed.110.085746

$\mathbf{R}$ adioactively labeled peptides have been recognized as an effective way to target cellular receptors in vivo for diagnostic identification and characterization and for targeted

Received Jul. 25, 2011; revision accepted Oct. 25, 2011.

For correspondence contact: Michael M. Graham, University of lowa

Hospitals and Clinics, 200 Hawkins Dr., lowa City, lowa 52242.

E-mail: michael-graham@uiowa.edu

COPYRIGHT @ 2011 by the Society of Nuclear Medicine, Inc. radiotherapy. Several peptides targeting a wide variety of receptors have been identified. Most of these have been relevant to tumors, but there are several potential applications of radiopeptides in nononcologic disease.

The 2 major advantages of peptides for receptor targeting are that they can be designed to essentially duplicate the critical region of the natural receptor ligand, thus achieving high specificity, and that they are relatively small, especially compared with antibodies, and therefore localize very rapidly. These advantages are significant for diagnostic imaging, leading to high sensitivity and specificity and to effective therapeutic agents that can achieve high tumor radiation doses.

The research and development of radiopeptides for diagnosis and therapy have been global efforts, with much of the early work taking place outside the United States. However, in recent years the research effort within the United States has accelerated. This article reviews that effort, both for diagnostic agents and for the use of radiopeptides in therapy. The agents discussed are summarized in Table 1.

\section{IMAGING WITH SOMATOSTATIN RECEPTOR LIGANDS}

The most widely used radiopeptide in the United States is the ${ }^{111}$ In-labeled somatostatin analog pentetreotide (OctreoScan; Covidien), which was approved by the U.S. Food and Drug Administration (FDA) in 1994 as an agent for the scintigraphic localization of primary and metastatic neuroendocrine tumors bearing somatostatin receptors. ${ }^{111}$ In-pentetreotide (also known as ${ }^{111} \mathrm{In}$ octreotide) has the highest affinity for receptor subtype 2 , lower affinities for subtypes 3 and 5, and the lowest affinity for subtypes 1 and 4 (1).

Somatostatin in humans occurs as both 28-amino-acid and 14-amino-acid proteins. Octreotide is a diethylenetriaminepentaacetic acid conjugate of 8 of the amino acids from somatostatin that specifically target somatostatin receptors. The 8-peptide sequence of amino acids in octreotide is D-phenylalanine-L-cysteine-L-phenylalanineD-tryptophan-L-lysine-L-threonine-L-cysteine-L-threonine.

The tumor types studied with octreotide include carcinoid, growth hormone-secreting pituitary tumors, endocrine pancreatic tumors, paraganglioma, medullary thyroid carcinoma, pheochromocytoma, small cell lung carcinoma, neuroblastoma, meningioma, and Merkel cell tumors. Octreotide has been used most successfully for carcinoid, endocrine pancreatic tumors, and neuroblastoma. 
TABLE 1

Summary of Radiolabeled Peptides

\begin{tabular}{|c|c|c|c|c|c|c|c|}
\hline Peptide & $\begin{array}{l}\text { No. of } \\
\text { amino } \\
\text { acids }\end{array}$ & Isotope(s) & $\begin{array}{l}\text { Mechanism } \\
\text { of binding }\end{array}$ & Tumor(s) & $\begin{array}{l}\text { Human } \\
\text { studies }\end{array}$ & $\begin{array}{l}\text { Approval } \\
\text { status }\end{array}$ & Reference(s) \\
\hline Pentetreotide & 8 & ${ }^{111} / \mathrm{n}$ & $\begin{array}{l}\text { Somatostatin } \\
\text { receptor subtype } 2\end{array}$ & Carcinoid & Yes & Approved & $2-8$ \\
\hline DOTATOC & 8 & ${ }^{68} \mathrm{Ga}$ & $\begin{array}{l}\text { Somatostatin } \\
\text { receptor subtype } 2\end{array}$ & Carcinoid & Yes & $\begin{array}{c}\text { Radioactive Drug } \\
\text { Research Committee } \\
\text { approval }\end{array}$ & 20,21 \\
\hline DOTATATE & 8 & ${ }^{68} \mathrm{Ga}$ & $\begin{array}{l}\text { Somatostatin } \\
\text { receptor subtype } 2\end{array}$ & Carcinoid & Yes & $\begin{array}{l}\text { Investigational New } \\
\text { Drug authorization }\end{array}$ & \\
\hline Depreotide & 8 & 99mTc & $\begin{array}{l}\text { Somatostatin } \\
\text { receptor subtype } 2\end{array}$ & Carcinoid & Yes & $\begin{array}{l}\text { Approved but no } \\
\text { longer available }\end{array}$ & $13-16$ \\
\hline$\alpha-\mathrm{MSH}$ analog & 13 & $\begin{array}{l}{ }^{111} \mathrm{In},{ }^{68} \mathrm{Ga} \\
{ }^{86} \mathrm{Y},{ }^{18} \mathrm{~F}\end{array}$ & MSH receptor & Melanoma & No & Not approved & $24-26$ \\
\hline RGD & 3 & $\underset{125}{{ }^{18} \mathrm{~F},}$ & Neoangiogenesis & $\begin{array}{l}\text { Glioma, } \\
\text { melanoma }\end{array}$ & No & Not approved & $27-32$ \\
\hline Bombesin & 14 & $\begin{array}{c}{ }^{188} \mathrm{Re},{ }^{99 m \mathrm{Tc}}, \\
{ }^{64} \mathrm{Cu},{ }^{177} \mathrm{Lu}\end{array}$ & $\begin{array}{l}\text { Gastrin-releasing } \\
\text { peptide (GRP) } \\
\text { receptor }\end{array}$ & $\begin{array}{l}\text { Prostate, } \\
\text { breast }\end{array}$ & $\begin{array}{l}\text { Outside } \\
\text { United } \\
\text { States }\end{array}$ & Not approved & $35-41$ \\
\hline RGD-bombesin dimer & 3 and 14 & $\begin{array}{l}{ }^{18} \mathrm{~F},{ }^{64} \mathrm{Cu} \\
{ }^{68} \mathrm{Ga}\end{array}$ & $\begin{array}{l}\text { Neoangiogenesis } \\
\text { and GRP receptor }\end{array}$ & Breast & No & Not approved & 33,34 \\
\hline $\begin{array}{l}\text { Escherichia coli heat-stable } \\
\text { enterotoxin }\end{array}$ & 19 & ${ }^{111} / \mathrm{n}$ & $\begin{array}{l}\text { Guanylate cyclase } \\
\text { C receptor }\end{array}$ & Colorectal & No & Not approved & 42 \\
\hline $\begin{array}{l}\text { Vasoactive intestinal peptide } \\
\quad \text { (VIP) }\end{array}$ & 28 & ${ }^{123} \mathrm{I},{ }^{64} \mathrm{Cu}$ & VIP receptor & Prostate & No & Not approved & 43 \\
\hline $\begin{array}{l}\text { Pituitary adenylate cyclase- } \\
\text { activating peptide } \\
\text { (PACAP) }\end{array}$ & 27 & ${ }^{99 \mathrm{mT}} \mathrm{T},{ }^{64} \mathrm{Cu}$ & PACAP receptor & Breast & No & Not approved & 43 \\
\hline
\end{tabular}

\section{IN-LABELED SOMATOSTATIN RECEPTOR IMAGING}

The first published report on the use of ${ }^{111}$ In-octreotide imaging in humans in the United States was from a group of investigators at the Mayo Clinic in 1995 (2). They studied a single patient with cholangiocarcinoma and demonstrated uptake in the tumor.

At the University of Ohio, Martinez et al. conducted the first study of a series of patients with radiolabeled octreotide in the United States (3). They studied 6 children with neuroblastoma by using ${ }^{125} \mathrm{I}$-Tyr3-octreotide and intraoperative exploration with a $\gamma$-probe. Seventeen sites of radiotracer binding were identified, for a sensitivity of $100 \%$ and a specificity of $71 \%$.

The first U.S. report on the use of ${ }^{111}$ In-octreotide in carcinoid imaging was from investigators at Vanderbilt University (4). They studied 69 patients with neuroendocrine tumors (among them 60 carcinoids) and showed that ${ }^{111} \mathrm{In}$-octreotide identified additional sites of metastasis in 12 .

The first large clinical trial with ${ }^{111}$ In-octreotide in the United States was conducted at the National Institutes of Health and included 80 consecutive patients with Zollinger-Ellison syndrome (5). This trial showed that somatostatin receptor scintigraphy was markedly more sensitive than ultrasonography, CT, MRI, or angiography, detecting extrahepatic gastrinomas or liver metastases in $70 \%$ of the patients.

${ }^{111}$ In-octreotide imaging of paraganglioma in the neck has been a particularly successful application of the tech- nique. In the United States, this application was recognized as being important because of a study done at the University of Miami and published in 2004 (6). Sixty patients with suspected neuroendocrine tumors of the neck were studied. ${ }^{111}$ In-octreotide scintigraphy had a sensitivity of $97 \%$ and a specificity of $82 \%$.

Since the 1990s, numerous studies on the clinical utility of ${ }^{111}$ In-octreotide at sites in the United States have continued to be published. Notable recent articles described the added value of CT when combined with SPECT-now available in modern SPECT/CT systems (7) - and the observations that ${ }^{18} \mathrm{~F}$-FDG uptake was higher in more poorly differentiated neuroendocrine tumors whereas ${ }^{111} \mathrm{In}$-octreotide uptake was higher in better-differentiated tumors (8). This point is important because tumors with high ${ }^{18} \mathrm{~F}$-FDG uptake have a significantly worse prognosis that those with low uptake (9).

\section{MTC-LABELED SOMATOSTATIN RECEPTOR IMAGING}

In the mid-1990s, several radiochemistry studies examining the feasibility of labeling octreotide and other peptides with ${ }^{99 \mathrm{~m}} \mathrm{Tc}$ were reported by U.S. investigators $(10-12)$. All of these reports, including both in vitro and in vivo studies, showed convincingly that ${ }^{99 \mathrm{~m}} \mathrm{Tc}$-labeled peptides were stable and that they bound to somatostatin receptors with a high affinity. The ratios of target uptake to nontarget uptake were generally better than those obtained with ${ }^{111}$ In-octreotide, and the tumor-to-blood ratios were lower. 
A ${ }^{99 \mathrm{~m}}$ Tc-labeled octreotide analog developed as ${ }^{99 \mathrm{~m}} \mathrm{Tc}-$ depreotide (NeoTect [Diatide Inc.]; NeoSpect [Nycomed]) was approved by the FDA late in 1999 for the characterization of pulmonary nodules. The first report of a clinical trial of ${ }^{99 \mathrm{~m}} \mathrm{Tc}$-depreotide in the United States was from Blum et al. in 1999 (13). The agent was designated P829 at that time. They studied 30 subjects who had indeterminate pulmonary nodules with an average size of $2.4 \mathrm{~cm}$ $(\mathrm{SD}, 0.9 \mathrm{~cm})$. The sensitivity and specificity of ${ }^{99 \mathrm{~m} T \mathrm{~T}-\mathrm{dep}-}$ reotide for the diagnosis of malignancy in this pilot study were $93 \%$ and $88 \%$, respectively. A larger trial was done at the University of Iowa with 166 subjects who had suspected lung cancer (14). The performance of ${ }^{99 \mathrm{~m}} \mathrm{Tc}$-depreotide for the diagnosis of malignancy in pulmonary nodules or masses and the detection of mediastinal nodal metastasis was compared with that of ${ }^{18} \mathrm{~F}-\mathrm{FDG}$. The median size of the lung lesions was $2.2 \mathrm{~cm}$, with a range of $0.5-10.5 \mathrm{~cm}$. The sensitivity and specificity of ${ }^{99 \mathrm{~m}} \mathrm{Tc}$-depreotide for the diagnosis of malignancy in pulmonary lesions were $94 \%$ and $51 \%$, respectively; those of ${ }^{18} \mathrm{~F}-\mathrm{FDG}$ PET were $96 \%$ and $71 \%$, respectively. For the detection of mediastinal nodal metastasis, the respective sensitivity and specificity were $68 \%$ and $70 \%$ for ${ }^{99 m} \mathrm{Tc}$-depreotide and $81 \%$ and $77 \%$ for ${ }^{18}$ F-FDG PET (14).

In a small study of patients with lymphomas, good uptake of ${ }^{99 \mathrm{~m}} \mathrm{Tc}$-depreotide was observed in 7 of 9 patients. This finding led to the suggestion that $\beta$-emitting radiopeptides might be used for treatment in patients with lymphomas showing high uptake of the somatostatin receptor ligand (15).

${ }^{99} \mathrm{~m}$ Tc-depreotide has not been widely used in the United States in recent years and is currently not available for clinical use, probably because it emerged at the same time as ${ }^{18}$ F-FDG PET, which grew rapidly and was apparently more accurate in characterizing lung cancer. Because of the limited approved indications, ${ }^{99 \mathrm{~m} T c-d e p r e o t i d e ~ w a s ~ n e v e r ~ c a r e-~}$ fully studied for general neuroendocrine tumor imaging. There have been no recent reports of human imaging studies with ${ }^{99 \mathrm{~m}} \mathrm{Tc}$-labeled octreotide analogs from groups within the United States, although review of the literature reveals that these agents are being used in China for pheochromocytoma (16) and in Uruguay for neuroblastoma (17).

On October 28, 2010, the European Commission issued a decision to withdraw the marketing authorization for ${ }^{99 \mathrm{~m}} \mathrm{Tc}$-depreotide. This decision was apparently made in accordance with the manufacturer's request, which was based on commercial reasons.

\section{${ }^{68}$ GA-LABELED SOMATOSTATIN RECEPTOR IMAGING}

${ }^{68} \mathrm{Ga}$ (half-life, $68 \mathrm{~min}$ ) is a positron emitter and is obtained from a ${ }^{68} \mathrm{Ge}$ (half-life, $271 \mathrm{~d}$ ) generator. Several octreotide analogs have been labeled with ${ }^{68} \mathrm{Ga}$ and used in research and clinical applications outside the United States. Although all of the early work and clinical trials with ${ }^{68} \mathrm{Ga}-$ labeled somatostatin receptor agents took place outside the United States, effort in this area in the United States has not been entirely absent and is currently gathering momentum. Various reasons account for the delay of more than $10 \mathrm{y}$ in implementing human studies in the United States. These include the availability of ${ }^{68} \mathrm{Ga}$ generators and the regulatory requirements for first use in humans, uncertainty about the intellectual property ownership of various octreotide analogs and associated chelators, and general uncertainty about the regulations for manufacturing and using new radiopharmaceuticals, as well as recognition that the regulations are likely to change because the FDA was committed to updating the regulations under the Food and Drug Administration Modernization Act of 1997.

Radiopharmaceutical manufacturers have also delayed working toward approval of these agents for somewhat similar reasons, including uncertainty about intellectual property issues and the likelihood that regulations will change. In addition, economic analysis has suggested that, because of the relatively small numbers of patients with neuroendocrine tumors, the potential market may not be sufficient to justify all of the development expenses.

The current situation has definitely improved. The FDA has announced a new set of regulations for manufacturing PET radiopharmaceuticals, which will take effect in late 2011. ${ }^{68} \mathrm{Ga}$ generators are now available from one company, and it is likely that other suppliers will enter the market in the United States in the near future. At least 2 U.S. academic sites are beginning to do human studiesVanderbilt University under an Investigational New Drug authorization and the University of Iowa under Radioactive Drug Research Committee approval. Figure 1 shows an example from the group at the University of Iowa that illustrates the higher quality of ${ }^{68} \mathrm{Ga}$-DOTATOC images than of ${ }^{111}$ In-octreotide images. It is likely that the number of sites in the United States conducting human studies will grow significantly in the next few years and that these agents will become important tools in the diagnosis of and follow-up for neuroendocrine tumors.

Human ${ }^{68} \mathrm{Ga}$ studies were done in the United States as early as 1978 (18), but all of the early studies were done with ${ }^{68} \mathrm{Ga}$-ethylenediaminetetraacetic acid as a measure of vascular permeability in the brain. In the $1980 \mathrm{~s},{ }^{68} \mathrm{Ga}$-labeled transferrin was used to study pulmonary blood flow and vascular permeability $(19,20)$. At present there are apparently no reports from groups within the United States on human studies with ${ }^{68} \mathrm{Ga}$-labeled somatostatin receptor ligands. However, several preclinical studies have been reported.

The first published report on gallium-labeled somatostatin receptor ligands in the United States was from the Memorial Sloan-Kettering Cancer Center in 2002 (21). The investigators showed successful labeling of DOTATOC (DOTA-DPhe1-Tyr3-octreotide) with ${ }^{66} \mathrm{Ga},{ }^{67} \mathrm{Ga}$, and ${ }^{68} \mathrm{Ga}$ and rapid uptake in a rat pancreas tumor implanted into nude mice.

Although several reports from groups in the United States described studies involving ${ }^{68} \mathrm{Ga}$-labeled peptides, the only other report on ${ }^{68} \mathrm{Ga}$-labeled somatostatin receptor 


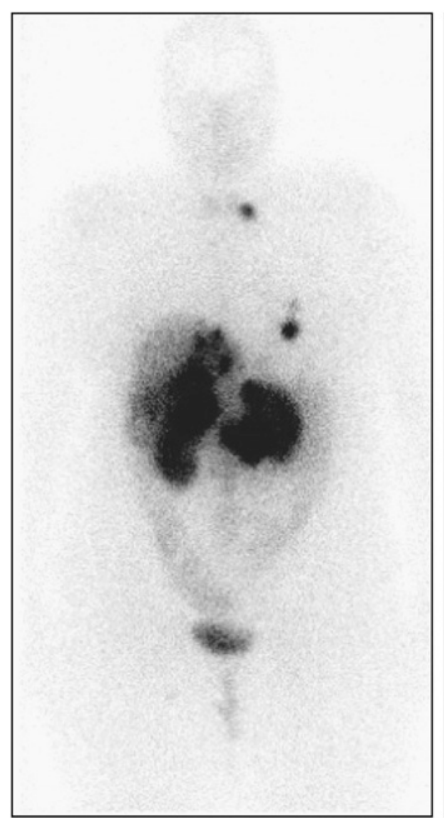

In-111 Octreotide Anterior Planar

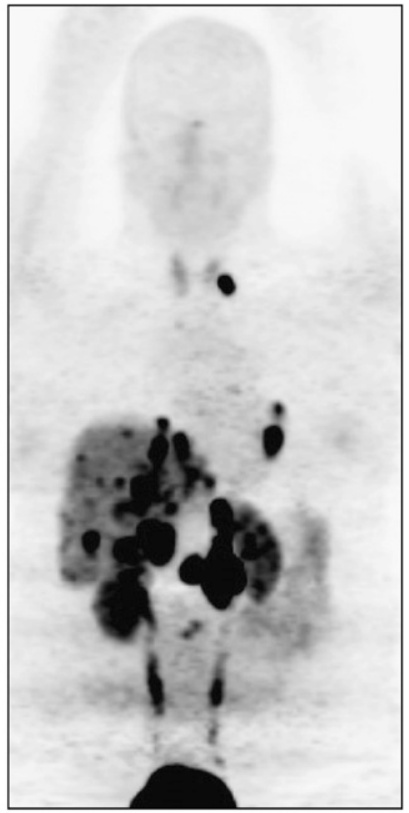

Ga-68 DOTATOC MIP
FIGURE 1. Comparison of ${ }^{111} \mathrm{In}$-octreotide image obtained at $24 \mathrm{~h}$ after injection with ${ }^{68} \mathrm{Ga}$-DOTATOC image obtained at $1 \mathrm{~h}$ after injection. Subject was $35-y$-old man with metastatic gastrinoma. MIP = maximum-intensity projection.

ligands appears to be from researchers at the Memorial Sloan-Kettering Cancer Center in 2011 (22). They reported on the use of ${ }^{68} \mathrm{Ga}$-DOTATOC for the imaging of a reporter gene that results in the expression of somatostatin receptor subtype 2 in transfected cells.

\section{PEPTIDE IMAGING OF MELANOMA}

The first published study of peptide-based imaging of melanoma was from a group of investigators at Oregon Health Sciences University (23). Uptake of ${ }^{111}$ In-octreotide was shown in 12 of 16 patients with metastatic melanoma. Although their study clearly showed that such imaging is feasible and that melanoma often expresses somatostatin receptors, this line of research has not been significantly pursued. Rather, a more direct approach with ligands targeted to the melanocyte-stimulating hormone (MSH) receptor (also called melanocortin) is currently being pursued at several universities in the United States.

A group of investigators at Washington University in St. Louis, Missouri, reported tumor uptake in mice as well as the biodistribution of a ${ }^{68} \mathrm{Ga}$-labeled DOTA-rhenium-cyclized $\alpha$-MSH analog (24). This agent showed promise for the early detection of malignant melanoma. A novel $\alpha$-MSH peptide analog labeled with ${ }^{111} \mathrm{In},{ }^{86} \mathrm{Y}$, and ${ }^{68} \mathrm{Ga}$ also showed promise as a possible melanoma imaging agent in studies by the same group (25).

The radiochemistry group at the University of Missouri also investigated an analog for MSH (26). Their work involved a high-specific-activity ${ }^{68} \mathrm{Ga}$-labeled DOTA-rhenium-cyclized $\alpha$-MSH peptide analog. The initial studies, with small-animal imaging, showed a high ratio of tumor uptake to nontumor uptake at $1 \mathrm{~h}$ after injection.

Researchers at Stanford University studied several approaches for imaging melanoma. Recently, they reported an animal study with ${ }^{18} \mathrm{~F}$-labeled metallopeptides targeted to the MSH receptor (27). Good uptake was observed in tumor-bearing mice, suggesting that the agent may be useful clinically.

\section{PEPTIDE IMAGING OF ANGIOGENESIS}

Another oligopeptide that may become an important and useful clinical tool is the arginine-glycine-aspartate (RGD) sequence. Numerous studies have shown that this small peptide sequence binds avidly to the endothelium in regions of neoangiogenesis. The agent is likely to be useful in oncology-for visualizing where tumors are generating new blood vessels-but also in nonmalignant diseasewhen there is either too little (infarct repair) or too much (macular degeneration) angiogenesis.

The initial studies in the United States, investigating the feasibility of labeling the RGD sequence with ${ }^{18} \mathrm{~F},{ }^{64} \mathrm{Cu}$, and ${ }^{125}$ I, were done at the University of Southern California (28). Much of the more recently published work was done at Stanford University (29). In addition, investigations were also carried out at the University of Texas M.D. Anderson Cancer Center (30), Washington University (31), University of California-Davis (32), University of California-Los Angeles (33), and Purdue University (34). Most of these studies showed good tumor uptake with small-animal imaging.

\section{TUMOR IMAGING WITH PEPTIDE DIMERS}

In many recent studies, the RGD peptide was combined with a second peptide with a different target to increase the specificity of tumor binding.

A group of researchers at Stanford University investigated cyclic RGD dimers in combination with bombesin, which targets the gastrin-releasing peptide receptor. They recently labeled the RGD-bombesin heterodimer with ${ }^{18} \mathrm{~F},{ }^{64} \mathrm{Cu}$, and ${ }^{68} \mathrm{Ga}$ (35). The 3 agents were studied both in vitro and in vivo. The in vivo studies were done with breast cancer xenografts in nude mice. The ${ }^{68} \mathrm{Ga}$-labeled agent showed somewhat higher tumor uptake, but the ratio of tumor uptake to nontumor uptake was better with the ${ }^{18} \mathrm{~F}$-labeled agent. The results are definitely encouraging, but clinical trials are required to determine the optimum approach.

A group at Purdue University is investigating RGD dimers labeled with ${ }^{99 \mathrm{~m}} \mathrm{Tc},{ }^{64} \mathrm{Cu}$, and ${ }^{111} \mathrm{In}$ (34). In both in vitro and in vivo animal studies, the dimers showed more specific uptake than the monomers. The distance between the 2 RGD elements in the dimers is a critical parameter that may be optimized. This aspect is a particular focus of all of the groups working with dimers.

\section{BOMBESIN}

Bombesin is a 14-amino-acid peptide that binds with a high affinity to the receptors for gastrin-releasing peptide and neuromedin B and is overexpressed on a variety of solid 
tumors. Various bombesin analogs have been studied, with much of the earliest work taking place within the United States. In 1997, a group at the University of Alabama described the process for labeling a 7-amino-acid analog of bombesin with ${ }^{188} \mathrm{Re}$ and reported binding to prostate cancer cells (36).

In 1998, a group at Johns Hopkins University described the synthesis of a bombesin analog conjugated to ${ }^{99 \mathrm{~m}} \mathrm{Tc}$ (37). That group continued to develop ${ }^{99 \mathrm{~m} T c-l a b e l e d ~ b o m-~}$ besin and, more recently, described in vitro binding to prostate cancer cells along with in vivo imaging in SCID mice with PC-3 prostate cancer xenografts (38). Other work with ${ }^{99 m}$ Tc-labeled bombesin analogs is under way at Missouri University. Researchers there developed a new method for conjugating ${ }^{99 \mathrm{~m}} \mathrm{Tc}$ to bombesin analogs and reported good localization in breast cancer xenografts in mice (39).

Several other approaches for labeling bombesin have also been explored. Parry et al., at Washington University, evaluated a ${ }^{64} \mathrm{Cu}$-labeled DOTA linker for bombesin in both in vitro and in vivo animal studies of prostate cancer and reported excellent uptake and retention (40). The work with ${ }^{64} \mathrm{Cu}$-labeled bombesin analogs is reviewed in detail in an article from the group at the University of Missouri (41).

Radiolabeled bombesin analogs are also being studied as possible therapeutic agents. Initial studies with a ${ }^{177} \mathrm{Lu}$-labeled agent in prostate cancer cell lines and in in vivo studies of mice with prostate cancer xenografts showed good uptake and response to therapy (42).

\section{OTHER RECEPTORS}

Additional studies investigating several other receptor systems, generally those that are overexpressed in a variety of cancers, are under way. An example of such work was reported recently by Praharaj et al., from Columbia, Missouri (43). They studied peptides targeting guanylate cyclase $\mathrm{C}$ and the urokinase-type plasminogen activator receptor.

Other investigators studied radiolabeled analogs of vasoactive intestinal peptide and pituitary adenylate cyclaseactivating peptide to target their respective receptors, which appear to be upregulated in breast cancer (44).

\section{RADIOLABELED PEPTIDE THERAPY IN UNITED STATES}

Because the only FDA-approved radiolabeled peptide for imaging in the Unites States is ${ }^{111}$ In-octreotide, the first clinical studies of peptide receptor radionuclide therapy (PRRT) were done with high-dose ${ }^{111}$ In-octreotide. In 2002, Anthony et al. reported on 27 patients with gastroenteropancreatic neuroendocrine tumors treated with ${ }^{111} \mathrm{In}$ octreotide in a phase II trial at Louisiana State University (45). For these patients, conventional therapies had failed and radiographic or clinical disease progression was evident. The initial dose of ${ }^{111} \mathrm{In}$-octreotide was $6,660 \mathrm{MBq}$, a second dose of $6,660 \mathrm{MBq}$ was given $30 \mathrm{~d}$ later, and the therapy was repeated if patients responded to the initial dose, with a total dosage per patient ranging from 6,660 to $46,620 \mathrm{MBq}$ (mean, 13,320 MBq). The investigators observed one case of grade 3 leukopenia, one case of grade 4 thrombocytopenia, and one grade 3 increase in the serum creatinine level, which were probably related to the therapy. Only $8 \%$ of patients showed a partial response radiographically; however, $62 \%$ of patients had clinical improvement (a decrease in the narcotic analgesic dose or an improvement in the Karnofsky score), and $81 \%$ had a biochemical response.

In 2008, Delpassand et al. reported similar results, in terms of toxicity and efficacy, with ${ }^{111}$ In-octreotide in 32 patients who had progressive neuroendocrine tumors and who received 1 therapy (14 patients) or 2 therapies (18 patients) with $18,500 \mathrm{MBq}$ of the radiopharmaceutical (46). There were no grade 4 toxicities, and only 1 patient developed grade 3 thrombocytopenia. A partial response was demonstrated radiographically in $11 \%$ of patients; the remaining patients achieved stable disease, with a radiologic response being observed for up to 17 mo after therapy. A clinical response was reported in $83 \%$ of patients, with $77 \%$ showing a significant decrease in the tumor marker or hormone level.

The main limitation of ${ }^{111} \mathrm{In}$-octreotide is the short range of the auger electrons emitted by ${ }^{111} \mathrm{In}(<10 \mathrm{~nm})$, which have very limited tissue penetration. This limitation has led to the development of somatostatin analogs radiolabeled with high-energy $\beta$-emitters (such as ${ }^{90} \mathrm{Y}$ and ${ }^{177} \mathrm{Lu}$ ). Currently, no somatostatin analogs radiolabeled with $\beta$-emitters are approved by the FDA for clinical use; however, ${ }^{90}$ Y-DOTATOC and ${ }^{177} \mathrm{Lu}$-DOTATATE have been designated as orphan drugs by the FDA. The available clinical data from the United States on PRRT with these compounds are primarily from several multiinstitutional trials with participation by U.S. and European centers.

The University of Iowa was a major participant in a multicenter phase II trial evaluating the efficacy of ${ }^{90}$ Y-DOTA-Tyr3-octreotide ( ${ }^{90}$ Y-DOTATOC, also designated ${ }^{90}$ Y-edotreotide; Onalta [Molecular Insight Pharmaceuticals]) in 90 patients with metastatic carcinoid tumors treated in multiple centers in the United States and Europe. The results were published in 2010 (47). All patients had measurable disease and at least one symptom or sign refractory to optimal therapy with nonradioactive octreotide. Patients were treated with 3 cycles of ${ }^{90}$ Y-DOTATOC at 4,440 MBq per cycle, administered every 6-9 wk. Stable disease was observed in $70 \%$ of the patients after treatment; there were no complete responses, and there were $4.4 \%$ partial responses, according to Southwestern Oncology Group criteria (47). However, patients reported significant symptomatic improvement, with a mean duration of the clinical response of 8-12 wk. Furthermore, patients with a long-lasting improvement of diarrhea showed significantly better survival than patients without a long-lasting diarrhea response (18.2 vs. $7.9 \mathrm{mo})$. There were no grade 3 or 4 cases of leukopenia or thrombocytopenia. Side effects were mostly transient gastrointestinal tract symptoms (nausea, vomiting, and abdominal pain) related to the amino acid infusion (Aminosyn II; Abbott Laboratories; equivalent of $2 \mathrm{~L}$ over $4 \mathrm{~h}$ ) used for renal protection. 
The amino acid infusion is essential for reducing radiation injury to the kidneys in PRRT. Positively charged amino acids decrease the proximal tubular reabsorption of low-molecular-weight proteins and peptides, including radiolabeled somatostatin analogs (48). Bushnell et al. demonstrated a $32 \%$ reduction in the renal uptake of ${ }^{90}$ Y-DOTATOC with an amino acid infusion (Aminosyn II; $2 \mathrm{~L}$ over $4 \mathrm{~h}$ ) that contained $29 \mathrm{~g}$ of both arginine and lysine and $140 \mathrm{~g}$ of additional amino acids (49). This solution was used in the United States because of its commercial availability; however, its higher osmolarity is likely responsible for the higher incidence of nausea or vomiting seen with this solution than with a solution that contains 25 $\mathrm{g}$ of both arginine and lysine and that is also more effective in reducing the renal uptake of radiolabeled peptides (50). Despite the infusion of an amino acid solution, renal toxicity remains the most common long-term side effect of ${ }^{90}$ Y-DOTATOC therapy, with approximately $10 \%$ of patients developing permanent grade 4 or 5 renal toxicity (51).

The clinical effectiveness of PRRT was also evaluated with a clinical response scoring system in 21 patients with neuroendocrine tumors treated at the University of Iowa and VAMC Iowa City as part of the multicenter phase II trial of ${ }^{90}$ Y-DOTATOC (52). The scoring system included evaluations of weight change, tumor-related symptoms (fatigue, abdominal pain, diarrhea, nausea or vomiting, and flushing), the Karnofsky score, and a patient-reported health state score. Of the 21 patients included in the analysis, $67 \%$ showed a favorable clinical response, with a significant decrease in the daily nonradioactive octreotide requirement.

Similar response rates were reported in a phase I study of 58 patients treated at Lee Moffitt Cancer Center at the University of Florida; Erasmus Medical Center, Rotterdam, The Netherlands; and Catholic University of Louvain, Brussels, Belgium (53). Of 36 symptomatic patients at baseline, 58\% showed an improvement in clinical symptoms or the Karnofsky score; an objective response (Southwestern Oncology Group criteria) was noted in 57\% of patients, who converted either from progressive disease to stable disease of from stable disease to a minimal response (53).

The results of a phase I clinical trial of PRRT in pediatric patients at the University of Iowa were recently published. Menda et al. reported on 17 children and young adults who had 7 neuroendocrine tumors, 4 brain tumors, 3 paragangliomas, and 2 neuroblastomas and who were treated with ${ }^{90}$ Y-DOTATOC in a dose escalation phase I trial (54). The dose of ${ }^{90}$ Y-DOTATOC started at $1,110 \mathrm{MBq} / \mathrm{m}^{2}$ per cycle and increased to $1,850 \mathrm{MBq} / \mathrm{m}^{2}$ per cycle, administered in 3 cycles with a 6-wk period between the cycles. There was no dose-limiting toxicity. There was significant variability in the renal radiation doses among the patients, suggesting that a dosimetry-based approach would be preferable to fixed dosing with ${ }^{90}$ Y-DOTATOC. The treatment responses-12\% partial response, 29\% minimal response, and $35 \%$ stable disease-warranted a phase II trial of ${ }^{90} \mathrm{Y}-$
DOTATOC in children (54). More recently, Gains et al. reported promising results for ${ }^{177} \mathrm{Lu}$-DOTATATE in children, with 5 of 6 patients developing stable disease in cases of refractory or relapsing high-risk neuroblastoma (55).

Another radiolabeled peptide that has been reported in a therapeutic clinical trial in the United States is ${ }^{188} \mathrm{Re}-$ P2045. This agent is an analog of ${ }^{99 \mathrm{~m} T c-d e p r e o t i d e}$ $(13,14)$. In a phase I trial, patients with metastatic or recurrent lung tumors that could not be treated surgically and that were demonstrated to have somatostatin receptors by positive ${ }^{99 \mathrm{~m}} \mathrm{Tc}-\mathrm{P} 2045$ imaging results were treated with escalating doses of ${ }^{188} \mathrm{Re}-\mathrm{P} 2045$ (56). Ten patients were treated with ${ }^{188} \mathrm{Re}-\mathrm{P} 2045$ at $1,110-3,330 \mathrm{MBq} / \mathrm{m}^{2} ; 5$ patients $\mathrm{did}$ not receive the therapeutic dose because of a lack of uptake of ${ }^{99 \mathrm{~m}} \mathrm{Tc}-\mathrm{P} 2045$ in the tumor or a projected renal dose of greater than $20 \mathrm{~Gy}$. Other than one case of grade 3 lymphopenia, there were no grade 3 or 4 toxicities definitely related to the study drug. Although there were no objective responses, 5 of 8 patients with progressive disease at baseline remained stable at $8 \mathrm{wk}$ after therapy (56).

\section{CONCLUSION}

It is apparent that many basic and clinical research groups within the United States and elsewhere are studying a broad variety of radiopeptides that either have already been shown useful in the clinical setting or appear to have a significant potential to be shown useful in the future.

The breadth of effort and large number of agents are both encouraging and discouraging. It is encouraging that several promising ligands with a significant potential to make a real difference in the management of disease and the treatment of patients are being developed. However, the fact that the number of agents being studied is large is discouraging because it suggests that less effort is concentrated on bringing any given agent all the way through clinical trials to final approval.

Current research funding, particularly from the National Institutes of Health, overemphasizes the importance of novelty in research projects. This emphasis has the effect, in the radiopeptide area, of fostering the development of numerous new agents but does not provide the infrastructure for the translational effort to bring the agents to approval. The regulatory requirements in the United States also restrict access to several radionuclide peptides that are being used as clinical tools in a growing number of institutions across Europe. This issue is potentially critical for patients who may benefit from PRRT and need to travel to Europe for this treatment. Future attempts to balance the effort in the field with appropriate clinical trials are important so that at least some of these remarkable agents can be made available to patients in the United States.

\section{ACKNOWLEDGMENT}

No potential conflict of interest relevant to this article was reported. 


\section{REFERENCES}

1. Bruns C, Weckbecker G, Raulf F, et al. Molecular pharmacology of somatostatin-receptor subtypes. Ann N Y Acad Sci. 1994;733:138-146.

2. Tan CK, Podila PV, Taylor JE, et al. Human cholangiocarcinomas express somatostatin receptors and respond to somatostatin with growth inhibition. Gastroenterology. 1995;108:1908-1916.

3. Martinez DA, O'Dorisio MS, O'Dorisio TM, et al. Intraoperative detection and resection of occult neuroblastoma: a technique exploiting somatostatin receptor expression. J Pediatr Surg. 1995;30:1580-1589.

4. Anthony LB, Martin W, Delbeke D, Sandler M. Somatostatin receptor imaging: predictive and prognostic considerations. Digestion. 1996;57(suppl 1):50-53.

5. Gibril F, Reynolds JC, Doppman JL, et al. Somatostatin receptor scintigraphy: its sensitivity compared with that of other imaging methods in detecting primary and metastatic gastrinomas - a prospective study. Ann Intern Med. 1996;125:26-34.

6. Bustillo A, Telischi F, Weed D, et al. Octreotide scintigraphy in the head and neck. Laryngoscope. 2004;114:434-440.

7. Wong KK, Cahill JM, Frey KA, Avram AM. Incremental value of 111-In pentetreotide SPECT/CT fusion imaging of neuroendocrine tumors. Acad Radiol. 2010;17:291-297.

8. Zalom ML, Waxman AD, Yu R, Lee J, Ih G, Wolin EM. Metabolic and receptor imaging in patients with neuroendocrine tumors: comparison of fludeoxyglucose-positron emission tomography and computed tomography with indium in 111 pentetreotide. Endocr Pract. 2009;15:521-527.

9. Binderup T, Knigge U, Loft A, Federspiel B, Kjaer A. ${ }^{18} \mathrm{~F}$-fluorodeoxyglucose positron emission tomography predicts survival of patients with neuroendocrine tumors. Clin Cancer Res. 2010;16:978-985.

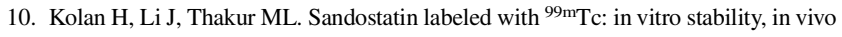
validity and comparison with ${ }^{111}$ In-DTPA-octreotide. Pept Res. 1996;9:144-150.

11. Pearson DA, Lister-James J, McBride WJ, et al. Somatostatin receptor-binding peptides labeled with technetium-99m: chemistry and initial biological studies. $J$ Med Chem. 1996;39:1361-1371.

12. Vallabhajosula S, Moyer BR, Lister-James J, et al. Preclinical evaluation of technetium-99m-labeled somatostatin receptor-binding peptides. J Nucl Med. 1996;37:1016-1022.

13. Blum JE, Handmaker H, Rinne NA. The utility of a somatostatin-type receptor binding peptide radiopharmaceutical (P829) in the evaluation of solitary pulmonary nodules. Chest. 1999;115:224-232.

14. Kahn D, Menda Y, Kernstine K, et al. The utility of ${ }^{99 \mathrm{~m}} \mathrm{Tc}$ depreotide compared with F-18 fluorodeoxyglucose positron emission tomography and surgical staging in patients with suspected non-small cell lung cancer. Chest. 2004;125:494-501.

15. Bushnell DL, Menda Y, Madsen MT, et al. ${ }^{99 \mathrm{~m}}$ Tc-depreotide tumour uptake in patients with non-Hodgkin's lymphoma. Nucl Med Commun. 2004;25:839-843.

16. Chen L, Li F, Zhuang H, Jing H, Du Y, Zeng Z. ${ }^{99 m}$ Tc-HYNIC-TOC scintigraphy is superior to ${ }^{131} \mathrm{I}-\mathrm{MIBG}$ imaging in the evaluation of extraadrenal pheochromocytoma. J Nucl Med. 2009;50:397-400.

17. Gambini JP, Lopez Lerena JJ, Quagliata A, Hermida JC, Heuguerot C, Alonso O. 99mTc-HYNIC octreotide in neuroblastoma. Ann Nucl Med. 2008;22:817-819.

18. Phelps ME, Hoffman EJ, Huang SC, Kuhl DE. ECAT: a new computerized tomographic imaging system for positron-emitting radiopharmaceuticals. $\mathrm{J} \mathrm{Nucl}$ Med. 1978;19:635-647.

19. Mintun MA, Ter-Pogossian MM, Green MA, Lich LL, Schuster DP. Quantitative measurement of regional pulmonary blood flow with positron emission tomography. J Appl Physiol. 1986;60:317-326.

20. Mintun MA, Dennis DR, Welch MJ, Mathias CJ, Schuster DP. Measurements of pulmonary vascular permeability with PET and gallium-68 transferrin. $\mathrm{J} \mathrm{Nucl}$ Med. 1987;28:1704-1716.

21. Ugur O, Kothari PJ, Finn RD, et al. Ga-66 labeled somatostatin analogue DOTADPhe1-Tyr3-octreotide as a potential agent for positron emission tomography imaging and receptor mediated internal radiotherapy of somatostatin receptor positive tumors. Nucl Med Biol. 2002;29:147-157.

22. Zhang H, Moroz MA, Serganova I, et al. Imaging expression of the human somatostatin receptor subtype-2 reporter gene with ${ }^{68} \mathrm{Ga}$-DOTATOC. $\mathrm{J}$ Nucl Med. 2011;52:123-131.

23. Fletcher WS, Lum SS, Nance RW, Pommier RF, O'Dorisio MS. The current status of somatostatin receptors in malignant melanoma. Yale J Biol Med. 1997;70:561-563.

24. Wei L, Miao Y, Gallazzi F, et al. Gallium-68-labeled DOTA-rhenium-cyclized alpha-melanocyte-stimulating hormone analog for imaging of malignant melanoma. Nucl Med Biol. 2007;34:945-953.

25. Wei L, Zhang X, Gallazzi F, et al. Melanoma imaging using ${ }^{111} \mathrm{In}-,{ }^{86} \mathrm{Y}$ - and ${ }^{68}$ Ga-labeled CHX-A"'-Re(Arg11)CCMSH. Nucl Med Biol. 2009;36:345-354.

26. Cantorias MV, Figueroa SD, Quinn TP, et al. Development of high-specificactivity ${ }^{68} \mathrm{Ga}$-labeled DOTA-rhenium-cyclized alpha-MSH peptide analog to target MC1 receptors overexpressed by melanoma tumors. Nucl Med Biol. 2009;36:505-513.

27. Ren G, Liu Z, Miao Z, et al. PET of malignant melanoma using ${ }^{18} \mathrm{~F}$-labeled metallopeptides. J Nucl Med. 2009;50:1865-1872.

28. Chen X, Park R, Shahinian AH, et al. ${ }^{18}$ F-labeled RGD peptide: initial evaluation for imaging brain tumor angiogenesis. Nucl Med Biol. 2004;31:179-189.

29. Wu Z, Li ZB, Chen K, et al. microPET of tumor integrin $\alpha_{v} \beta_{3}$ expression using ${ }^{18}$ F-labeled PEGylated tetrameric RGD peptide ( ${ }^{18}$ F-FPRGD4). J Nucl Med. 2007;48:1536-1544.

30. Li C, Wang W, Wu Q, et al. Dual optical and nuclear imaging in human melanoma xenografts using a single targeted imaging probe. Nucl Med Biol. 2006;33:349-358.

31. Sprague JE, Kitaura H, Zou W, et al. Noninvasive imaging of osteoclasts in parathyroid hormone-induced osteolysis using a ${ }^{64} \mathrm{Cu}$-labeled RGD peptide. $J$ Nucl Med. 2007;48:311-318.

32. Hausner SH, DiCara D, Marik J, Marshall JF, Sutcliffe JL. Use of a peptide derived from foot-and-mouth disease virus for the noninvasive imaging of human cancer: generation and evaluation of $4-\left[{ }^{18} \mathrm{~F}\right]$ fluorobenzoyl A20FMDV2 for in vivo imaging of integrin alphavbeta6 expression with positron emission tomography. Cancer Res. 2007;67:7833-7840.

33. Ferl GZ, Dumont RA, Hildebrandt IJ, et al. Derivation of a compartmental model for quantifying ${ }^{64} \mathrm{Cu}$-DOTA-RGD kinetics in tumor-bearing mice. $\mathrm{J} \mathrm{Nucl} \mathrm{Med}$. 2009;50:250-258.

34. Shi J, Wang L, Kim YS, et al. ${ }^{99 \mathrm{~m}} \mathrm{TcO}\left(\mathrm{MAG} 2-3 \mathrm{G} 3\right.$-dimer): a new integrin $\alpha_{\mathrm{v}} \beta_{3^{-}}$ targeted SPECT radiotracer with high tumor uptake and favorable pharmacokinetics. Eur J Nucl Med Mol Imaging. 2009;36:1874-1884.

35. Liu Z, Yan Y, Liu S, Wang F, Chen $X .{ }^{18} \mathrm{~F},{ }^{64} \mathrm{Cu}$, and ${ }^{68} \mathrm{Ga}$ labeled RGD-bombesin heterodimeric peptides for PET imaging of breast cancer. Bioconjug Chem. 2009;20:1016-1025.

36. Safavy A, Khazaeli MB, Qin H, Buchsbaum DJ. Synthesis of bombesin analogues for radiolabeling with rhenium-188. Cancer. 1997;80:2354-2359.

37. Baidoo KE, Lin KS, Zhan Y, Finley P, Scheffel U, Wagner HN Jr. Design, synthesis, and initial evaluation of high-affinity technetium bombesin analogues. Bioconjug Chem. 1998;9:218-225.

38. Lin KS, Luu A, Baidoo KE, et al. A new high affinity technetium-99m-bombesin analogue with low abdominal accumulation. Bioconjug Chem. 2005; $16: 43-50$.

39. Retzloff LB, Heinzke L, Figureoa SD, et al. Evaluation of $\left[{ }^{99 m} \mathrm{Tc}-(\mathrm{CO})_{3}-\mathrm{X}-\mathrm{Y}-\right.$ bombesin(7-14) $\mathrm{NH}_{2}$ ] conjugates for targeting gastrin-releasing peptide receptors overexpressed on breast carcinoma. Anticancer Res. 2010;30:19-30.

40. Parry JJ, Kelly TS, Andrews R, Rogers BE. In vitro and in vivo evaluation of ${ }^{64} \mathrm{Cu}$-labeled DOTA-linker-bombesin(7-14) analogues containing different amino acid linker moieties. Bioconjug Chem. 2007;18:1110-1117.

41. Hoffman TJ, Smith CJ. True radiotracers: Cu-64 targeting vectors based upon bombesin peptide. Nucl Med Biol. 2009;36:579-585.

42. Maddalena ME, Fox J, Chen J, et al. ${ }^{177}$ Lu-AMBA biodistribution, radiotherapeutic efficacy, imaging, and autoradiography in prostate cancer models with low GRP-R expression. J Nucl Med. 2009;50:2017-2024.

43. Praharaj S, Overbey D, Giblin MF. Radiometallated peptides targeting guanylate cyclase $\mathrm{C}$ and the urokinase-type plasminogen activator receptor. Future Oncol. 2010;6:1325-1337.

44. Zhang K, Aruva MR, Shanthly N, et al. Vasoactive intestinal peptide (VIP) and pituitary adenylate cyclase activating peptide (PACAP) receptor specific peptide analogues for PET imaging of breast cancer: in vitro/in vivo evaluation. Regul Pept. 2007;144:91-100.

45. Anthony LB, Woltering EA, Espenan GD, Cronin MD, Maloney TJ, McCarthy KE. Indium-111-pentetreotide prolongs survival in gastroenteropancreatic malignancies. Semin Nucl Med. 2002;32:123-132.

46. Delpassand ES, Sims-Mourtada J, Saso H, et al. Safety and efficacy of radionuclide therapy with high-activity In-111 pentetreotide in patients with progressive neuroendocrine tumors. Cancer Biother Radiopharm. 2008;23:292-300.

47. Bushnell DL Jr, O'Dorisio TM, O'Dorisio MS, et al. ${ }^{90}$ Y-edotreotide for metastatic carcinoid refractory to octreotide. J Clin Oncol. 2010;28:1652-1659.

48. Rolleman EJ, Melis M, Valkema R, Boerman OC, Krenning EP, de Jong M. Kidney protection during peptide receptor radionuclide therapy with somatostatin analogues. Eur J Nucl Med Mol Imaging. 2010;37:1018-1031.

49. Bushnell D, Menda Y, O'Dorisio T, et al. Effects of intravenous amino acid administration with Y-90 DOTA-Phe1-Tyr3-Octreotide (SMT487[OctreoTher] [sic]) treatment. Cancer Biother Radiopharm. 2004;19:35-41.

50. Rolleman EJ, Valkema R, de Jong M, Kooij PP, Krenning EP. Safe and effective inhibition of renal uptake of radiolabelled octreotide by a combination of lysine and arginine. Eur J Nucl Med Mol Imaging. 2003;30:9-15.

51. Imhof A, Brunner $\mathrm{P}$, Marincek $\mathrm{N}$, et al. Response, survival, and long-term toxicity after therapy with the radiolabeled somatostatin analogue $\left[{ }^{90} \mathrm{Y}\right.$ - 
DOTA]-TOC in metastasized neuroendocrine cancers. $J$ Clin Oncol. 2011;29:2416-2423.

52. Bushnell D, O'Dorisio T, Menda Y, et al. Evaluating the clinical effectiveness of ${ }^{90}$ Y-SMT 487 in patients with neuroendocrine tumors. $J$ Nucl Med. 2003;44:1556-1560.

53. Valkema R, Pauwels S, Kvols LK, et al. Survival and response after peptide receptor radionuclide therapy with [ ${ }^{90}$ Y-DOTA0,Tyr3] octreotide in patients with advanced gastroenteropancreatic neuroendocrine tumors. Semin Nucl Med. 2006;36:147-156.
54. Menda Y, O'Dorisio MS, Kao S, et al. Phase I trial of ${ }^{90}$ Y-DOTATOC therapy in children and young adults with refractory solid tumors that express somatostatin receptors. J Nucl Med. 2010;51:1524-1531.

55. Gains JE, Bomanji JB, Fersht NL, et al. ${ }^{177}$ Lu-DOTATATE molecular radiotherapy for childhood neuroblastoma. J Nucl Med. 2011;52:1041-1047.

56. Edelman MJ, Clamon G, Kahn D, Magram M, Lister-James J, Line BR. Targeted radiopharmaceutical therapy for advanced lung cancer: phase I trial of rhenium Re188 P2045, a somatostatin analog. J Thorac Oncol. 2009;4:15501554 